\title{
HIGH RESOLUTION TEM OBSERVATION AND EELS ANALYSIS OF CARBON NANOTUBES AT ELEVATED TEMPERATURES
}

\author{
T.Yaguchi*, T.Sato *, T.Kamino*, T.Hashimoto** , K.Motomiya ***, K.Tohji***, \\ A.Kasuya****
}

*Hitachi Science Systems, Ltd., 882 Ichige, Hitachinaka, Ibaraki, 312-8504 Japan

** Hitachi High-technologies cooperation, 882 Ichige, Hitachinaka, Ibaraki, 312-8504 Japan

*** Dept. of Geoscience and Technology, Tohoku Univ., Sendai, 980-8579, Japan

****Center for Interdisciplinary Research, Tohoku Univ., Sendai, 980-8578, Japan

Since the carbon nanotube was discovered under transmission electron microscope (TEM), high-resolution electron microscopy (HREM) has been a powerful technique to directly observe its fine structures. However, it was confirmed that the TEMs operated at more than $200 \mathrm{kV}$ generates electron beam damages during HREM observation [1]. In this study, we have applied high temperature TEM technique for HREM and electron energy loss spectroscopy (EELS) analysis of carbon nanotubes. Instruments used in the study were the Hitachi HF-2200 cold-FE analytical TEM and the Hitachi HD-2000 cold-FE scanning transmission electron microscope (STEM) equipped with a GATAN 666 digital PEELS system. A direct heating type specimen hot stage [2] was used in the experiment and specimens were mounted on the heating element of the hot stage directly. TEM image observation and EELS analysis were carried out under the various electron doses at $200 \mathrm{kV}$. The HREM images and EELS data obtained at elevated temperatures were compared with the ones obtained at room temperature.

Figure 1 shows HREM images (a, c) and EELS spectra $(b, d)$ of multi-walled carbon nanotubes (MWCNT) obtained at room temperature and at $600^{\circ} \mathrm{C}$, respectively. The total electron doses on the specimen were approximately $6 \times 10^{8}\left[\mathrm{e} / \mathrm{nm}^{2}\right]$. The crystal structure has changed into amorphous or amorphous-like structure and no typical electronic structure was obtained at room temperature. At $600^{\circ} \mathrm{C}$, the graphite structure was clearly observed and the sharp $\pi^{*}$ and $\sigma *$ peaks were obtained. Figure 2 shows HREM images and EELS spectra of single-walled carbon nanotubes (SWCNTs) obtained at room temperature (Fig. $2 \mathrm{a}, \mathrm{c}$ ) and at $900^{\circ} \mathrm{C}$ (Fig.2b, d), respectively. The total electron doses on the specimen were approximately $3 \times 10^{8}\left[\mathrm{e} / \mathrm{nm}^{2}\right]$ for HREM image observation and $1 \times 10^{8}$ $\left[\mathrm{e} / \mathrm{nm}^{2}\right]$ for EELS analysis. HREM image and broaden EELS peaks indicate that the structure of SWCNT was damaged at room temperature. At $900{ }^{\circ} \mathrm{C}$, however, a cap of the tube and graphene sheets are clearly observed, and the sharp $\pi^{*}$ and $\sigma *$ peaks were obtained. It is revealed that the structure of SWCNT was kept the same as MWCNT by heating.

The results of the experiment revealed that the specimen heating was also effective to prevent a contamination that may have adhered in the manufacturing process. In addition, no contamination 
occurred during HREM observation and EELS analyses at elevated temperatures. References

[1] D. Ugarte (1992) :Nature 359: 707-709.

[2] T.Kamino and H.Saka (1993) : Microsc. Microanal. Microstruct 4:127-135.
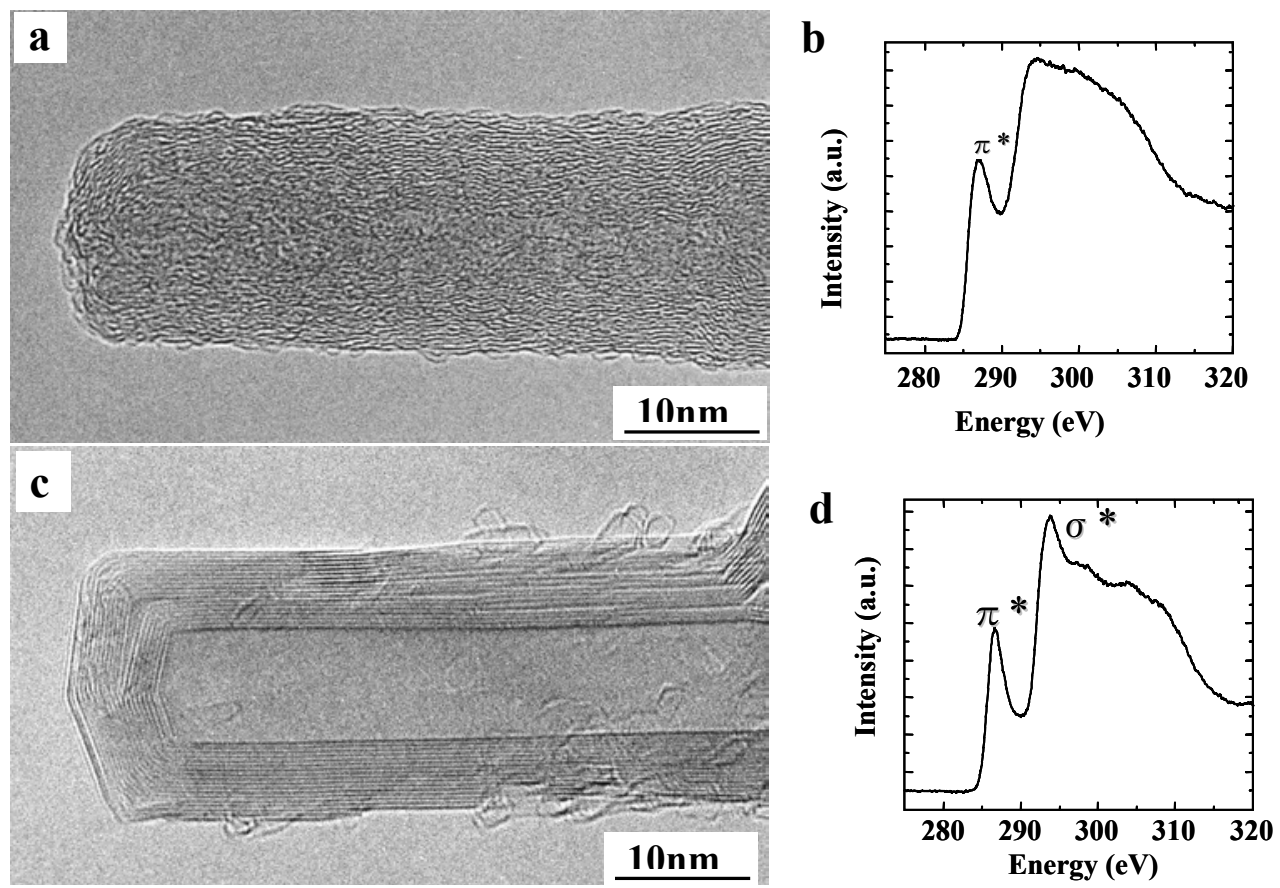

Fig. 1. HREM images $(\mathbf{a}, \mathbf{c})$ and EELS spectra $(\mathbf{b}, \mathbf{d})$ of MWCNTs.

a, b: at room temperature, $\mathbf{c}, \mathbf{d}$ : at $600^{\mathrm{L}}$.
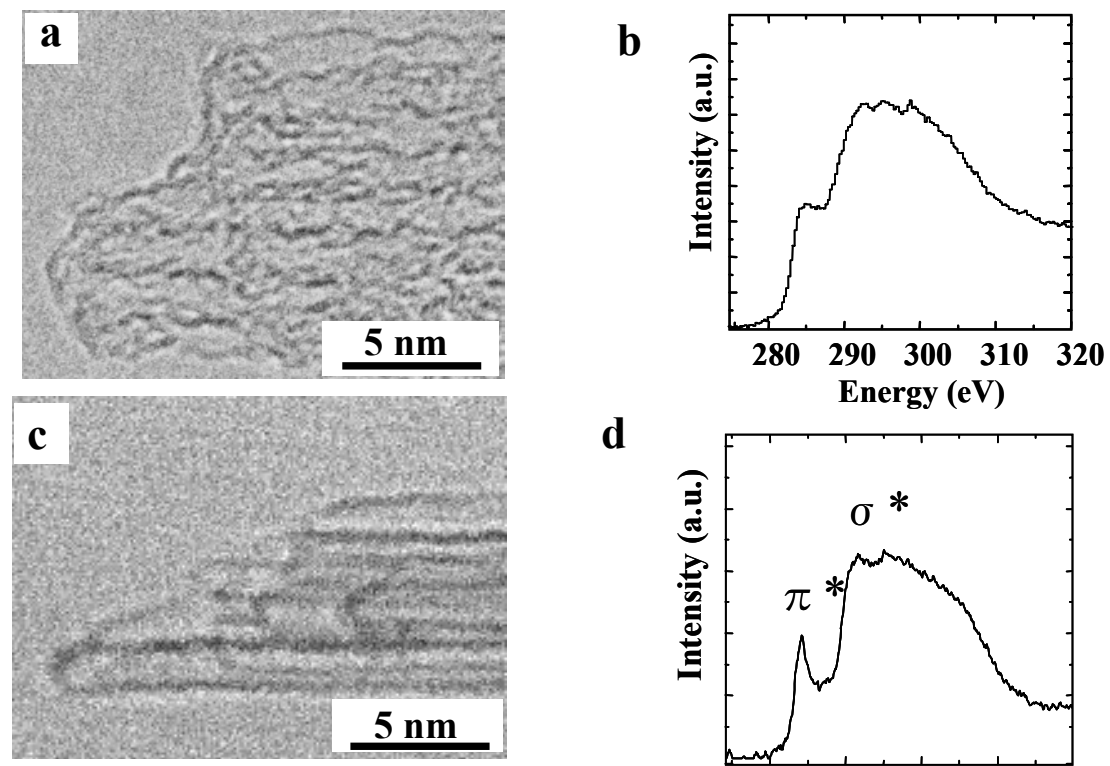

d

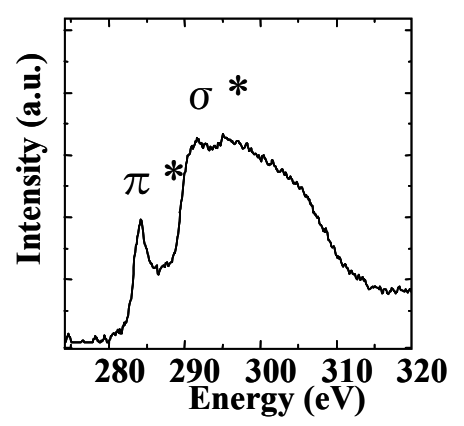

Fig. 2. HREM image (a, c) and EELS spectra $(\mathbf{b}, \mathbf{d})$ of SWCNTs.

a, b: at room temperature, $\mathbf{c}, \mathbf{d}$ : at $900^{\circ} \mathrm{C}$. 